\title{
Seleção em progênies de maracujazeiro-amarelo com base em índices multivariados
}

\author{
Eder Jorge de Oliveira(1), Vanderlei da Silva Santos( ${ }^{(1)}$, Diego Souza de Lima ${ }^{(2)}$, Marlos Dourado Machado(2), \\ Rangel Sales Lucena(2), Tiago Borges Nunes Motta ${ }^{(2)}$ e Milene da Silva Castellen ${ }^{(3)}$
}

\begin{abstract}
(1)Embrapa Mandioca e Fruticultura Tropical, Caixa Postal 007, CEP 44380-000 Cruz das Almas, BA. E-mail: eder@cnpmf.embrapa.br, vssantos@cnpmf.embrapa.br (2)Universidade Federal do Recôncavo da Bahia, Campus Universitário de Cruz das Almas, CEP $44380-000$ Cruz das Almas, BA. E-mail: diegodelima10@yahoo.com.br, marlosdourado@yahoo.com.br, rangel_lucena@yahoo.com.br, tico_motta@hotmail.com ${ }^{(3)}$ Embrapa Sede, Parque Estação Biológica, s/nº, CEP 70770-901 Brasília, DF. E-mail: milene.castellen@embrapa.br
\end{abstract}

Resumo - O objetivo deste trabalho foi avaliar os ganhos genéticos, preditos por meio de diferentes índices de seleção, em seis caracteres relacionados ao fruto, em 16 progênies de meios-irmãos de maracujá-amarelo. Foram utilizados: o índice clássico de Smith \& Hazel (IC) e a distância genótipo-ideótipo de Cruz (IDGI), ambos com três pesos econômicos; o índice de ganhos desejados de Pesek \& Baker (IGD); o índice livre de pesos e parâmetros de Elston (ILPP); e a seleção direta (SD). Observaram-se altas correlações genotípicas, de maior magnitude do que as fenotípicas, para algumas características, o que indica a existência de genes pleiotrópicos. Foram selecionadas cerca de 14\% das plantas, para intercruzamento e formação de novo ciclo de seleção. Os critérios de seleção foram divergentes, inclusive para o mesmo índice de seleção com diferentes pesos econômicos, o que revela alta divergência das progênies estudadas. A SD permitiu a obtenção de ganhos preditos desejáveis para todos os caracteres, porém em magnitudes inferiores a outros índices. Embora o IC tenha possibilitado a obtenção de maiores ganhos genéticos em relação ao peso e ao número de frutos por planta, houve ganho negativo para alguns caracteres. O IDGI foi superior na predição de maiores ganhos genéticos, de forma equilibrada para todos os caracteres, enquanto o ILPP mostrou o pior desempenho.

Termos para indexação: Passiflora edulis, meios-irmãos, melhoramento genético, variação genética.

\section{Selection on yellow passion fruit progenies by multivariate indices}

Abstract - The objective of this work was to evaluate the genetic gains predicted through different selection indices in 16 half-sib progenies of yellow passion fruit, using six fruit characteristics. The selection criteria used were: the classical index of Smith \& Hazel (CI) and the genotype-ideotype distance of Cruz (GID), both with three economic weights; the desired gain index of Pesek \& Baker (DGI); the weight-free index of Elston (WFI); and the direct selection (DS). High genotypic correlations, of greater magnitude than the phenotypic ones, were found for some characteristics, which indicates the presence of pleiotropic genes. About $14 \%$ of the plants were selected for intercrossing and formation of a new cycle of selection. The selection criteria used were very different from each other, even for the same selection index with different economic weights, which shows the high progenies divergence. Desirable genetic gains were obtained with DS, but with lower magnitude than other indices. Although the CI was the criterion that showed the highest genetic gains for weight and number of fruits per plant, there were negative gains for some characteristics. The GDI was the best criterion to perform a greater predicted and balanced genetic gains for all the characteristics, while the WFI showed the worse performance.

Index terms: Passiflora edulis, half-sib, genetic breeding, genetic variation.

\section{Introdução}

O gênero Passiflora é o maior e mais representativo da família Passifloraceae, que possui de 400 a 500 espécies, das quais aproximadamente $90 \%$ são originárias das Américas, e muitas delas nativas do Brasil (Inglez de Souza \& Meletti, 1997). Grande parte dessas espécies está dispersa no território nacional, o que confere ao país a condição de um dos principais centros de diversidade genética do gênero. É notória a ampla variabilidade natural do maracujazeiro-amarelo (Passiflora edulis Sims), passível de exploração no melhoramento genético (Martins et al., 2003b; Gonçalves et al., 2007).

Vários são os métodos de melhoramento aplicáveis ao maracujazeiro, com o objetivo de aumento da

Pesq. agropec. bras., Brasília, v.43, n.11, p.1543-1549, nov. 2008 
freqüência de alelos favoráveis ou da exploração do vigor híbrido (Meletti et al., 2000). É possível obter populações melhoradas para diversos caracteres de interesse e, ainda, manter a variabilidade alélica para os locos de incompatibilidade (Suassuna et al., 2003).

O uso de progênies de meios-irmãos é comum no melhoramento da cultura, pela facilidade de obtenção dessas populações e pelo fato de se poderem estimar: a variância genética aditiva, a herdabilidade e, conseqüentemente, o progresso esperado com a seleção (Bruckner et al., 2002; Nascimento et al., 2003).

Após a constatação da existência de variabilidade, seja em populações naturais ou naquelas geradas a partir de cruzamentos controlados, devem-se utilizar diferentes estratégias para selecionar os melhores genótipos. A seleção direta e a indireta são as primeiras alternativas para obtenção de ganhos genéticos compensadores. Entretanto, como geralmente são analisados diversos caracteres, para agrupar em um único genótipo, e a resposta correlacionada à seleção dificulta o trabalho da própria seleção, os métodos de seleção univariada, na maioria das vezes, não permitem a obtenção de ganhos satisfatórios (Martins et al., 2003a). Assim, o uso de índices de seleção para múltiplos caracteres possibilita a obtenção de genótipos mais produtivos e adaptados, pela reunião de diversos atributos favoráveis (Silva, 1982; Cruz et al., 2004). Os índices de seleção permitem a utilização de um único valor para efetuar a seleção dos genótipos, uma vez que a análise é realizada por meio de combinações lineares dos dados fenotípicos dos diversos caracteres em estudo, cujos coeficientes de ponderação são estimados de modo a maximizar a correlação entre o índice e os valores genéticos verdadeiros dos candidatos à seleção (Garcia \& Souza Júnior, 1999; Cruz et al., 2004). O objetivo é a obtenção de valores agregados de maior confiabilidade, para se garantir a melhoria do valor genotípico populacional e o conseqüente sucesso no processo de seleção.

Smith (1936) propôs a teoria do índice de seleção, amplamente empregada no melhoramento de plantas. Esta técnica vem passando por modificações, avaliações e comparações com outros métodos de seleção, para que se possa garantir maior confiabilidade nos resultados (Martins et al., 2006; Gonçalves et al., 2007).

De forma geral, um índice de seleção deve permitir a classificação correta dos genótipos e considerar diversos caracteres simultaneamente (Cruz et al.,
2004). Atualmente, existem diferentes tipos de índices de seleção, disponíveis para uso em programas que envolvem as etapas de seleção e intercruzamento, a fim de se aumentarem as freqüências de alelos favoráveis para o conjunto de caracteres de importância. No caso do maracujá-amarelo, um dos objetivos do melhoramento é a obtenção de variedades com frutos alongados, que são preferidos pelo mercado consumidor e com frutos grandes e pesados, com cavidade interna profunda, completamente preenchida e bom rendimento de polpa, no caso do consumo in natura. Quando destinado à indústria, devem-se associar alto teor de sólidos solúveis (acima de $13^{\circ}$ brix), casca fina e maior rendimento de polpa (acima de $45 \%$ ).

O objetivo deste trabalho foi avaliar os ganhos genéticos preditos por diferentes índices de seleção, em seis caracteres relacionados ao fruto, em 16 progênies de meios-irmãos de maracujá-amarelo.

\section{Material e Métodos}

Foi utilizado um teste de 16 progênies de meiosirmãos de maracujá-amarelo, obtidas de uma população cultivada em área de produção da Empresa Cajuba, em Nova Soure, BA.

O ensaio foi instalado na área Experimental da Embrapa Mandioca e Fruticultura Tropical, Cruz

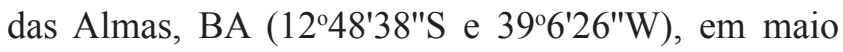
de 2007, em delineamento de blocos ao acaso, com três repetições e seis plantas úteis por parcela. O espaçamento utilizado foi de 2,6 m entre linhas e 3,7 $\mathrm{m}$ entre plantas. $\mathrm{O}$ sistema de condução utilizado foi espaldadeira vertical, com um fio de arame liso no 12 , a 2 m de altura do solo.

Os frutos da primeira safra foram colhidos entre dezembro de 2007 e março de 2008. Em cada planta, foram avaliados 10 frutos, com base nas seguintes características: peso de fruto; rendimento de polpa; comprimento dos frutos, obtido por meio da medição longitudinal dos frutos; largura de frutos, obtida por meio da medição transversal dos frutos; relação entre comprimento e largura dos frutos, mencionada como formato; e número de frutos por planta, obtido por meio de colheita durante todo o mês de pico de produção (janeiro de 2008).

A existência de variabilidade nas progênies de maracujá-amarelo foi verificada por meio da análise estatística, para cada característica, em 
plantas individuais, conforme o modelo estatístico $Y_{i j k}=\mu+p_{i}+b_{j}+e_{i j}+d_{i j k}$, em que: $Y_{i j k}$ é a observação da planta $\mathrm{k}$, da progênie i na repetição $\mathrm{j}$; $\mu$ é a média geral; $p_{i}$ é o efeito da progênie $i$; $b_{j}$ é o efeito da repetição $j$; $e_{i j}$ é o erro experimental associado à progênie $\mathrm{i}$, na repetição $\mathrm{j}$; $\mathrm{d}_{\mathrm{ijk}}$ é o efeito do indivíduo $\mathrm{k}$ da progênie $\mathrm{i}$, na repetição $\mathrm{j}$. Esses procedimentos foram realizados com o uso do programa computacional Genes (Cruz, 2006a, 2006b).

Foram selecionadas as 30 melhores plantas de maracujá-amarelo (14\% do total de plantas avaliadas), para posterior intercruzamento e formação do primeiro ciclo de seleção, entre e dentro de progênies de meios-irmãos. Foram estimados os ganhos por seleção direta entre progênies de meios-irmãos, para todos os caracteres avaliados, tendo-se considerado os desvios dos dados médios por planta, em relação ao limiar mínimo de seleção, peso de fruto - $149 \mathrm{~g}$; rendimento de polpa $-45 \%$; comprimento dos frutos $-74 \mathrm{~mm}$; largura de frutos $-72 \mathrm{~mm}$; formato do fruto - 1,03; e número de frutos por planta -47 . Todos os caracteres foram avaliados no sentido de acréscimo do caráter. $\mathrm{O}$ ganho por seleção direta foi estimado pela expressão $\Delta \mathrm{G} \%=100\left(\mathrm{ds} \times \mathrm{h}^{2}\right) \overline{\mathrm{X}}$, em que: $\Delta \mathrm{G} \%$ é o ganho esperado com a seleção, expresso em percentagem da média; ds é o diferencial de seleção; $h^{2}$ é o coeficiente de herdabilidade; e $\overline{\mathrm{X}}$ é a média original.

Além da seleção direta para os seis caracteres de frutos de maracujá-amarelo, o processo de seleção também foi realizado com base no índice livre de pesos e parâmetros (Elston, 1963), índice clássico (Smith, 1936; Hazel, 1943), índice da distância genótipo-ideótipo (Cruz, 2006a) e índice dos ganhos desejados (Pesek \& Baker, 1969).
Para a seleção com base no índice livre de pesos ou parâmetros (Elston, 1963), utilizaram-se os valores de $\mathrm{k}_{\mathrm{i}}$ iguais aos da seleção direta (149 g, peso de frutos; $45 \%$, rendimento de polpa; $74 \mathrm{~mm}$, comprimento de frutos; $72 \mathrm{~mm}$, largura de frutos; 1,03, formato de frutos; e 47, número de frutos por planta). Para a seleção com base no índice clássico (Smith, 1936; Hazel, 1943) e índice da distância genótipo-ideótipo (Cruz, 2006a), foram avaliados: os pesos econômicos iguais a um (IC-1 e IDGI-1, respectivamente) relativamente a cada característica; pesos econômicos iguais ao coeficiente de variação genética para cada característica (IC-2 e IDGI-2, respectivamente) e pesos econômicos de 2:1:1:1:1:2, para peso de fruto; rendimento de polpa; comprimento dos frutos; largura de frutos; formato do fruto e número de frutos por planta, respectivamente, com maior ponderação para peso e número de frutos por planta (IC-3 e IDGI-3, respectivamente). Ainda, com relação ao índice da distância genótipo-ideótipo, foram utilizados os mesmos valores de $\mathrm{k}_{\mathrm{i}}$ do índice livre de pesos ou parâmetros no processo de seleção. Quando se utilizou o índice dos ganhos desejados (Pesek \& Baker, 1969), os ganhos esperados foram equivalentes a um desvio-padrão genotípico.

\section{Resultados e Discussão}

Foram observadas diferenças significativas $(p>0,05)$ entre as progênies quanto aos caracteres: peso de fruto, rendimento de polpa, comprimento dos frutos e número de frutos por planta (Tabela 1). Em relação à largura de frutos e ao formato dos frutos, não houve diferença significativa entre as progênies. No entanto, a existência

Tabela 1. Resumo da análise de variância e estimativas de alguns parâmetros genéticos, referentes aos caracteres peso de fruto $(\mathrm{PF})$, rendimento de polpa $(\mathrm{RP})$, comprimento dos frutos $(\mathrm{CF})$, largura de frutos (LF), formato dos frutos (FF) e número de frutos por planta (NF), em progênies de meios-irmãos de maracujá-amarelo.

\begin{tabular}{|c|c|c|c|c|c|c|c|}
\hline \multirow[t]{2}{*}{ Fonte de variação $^{(1)}$} & \multirow[t]{2}{*}{ GL } & \multicolumn{6}{|c|}{ Quadrado médio } \\
\hline & & PF & RP & $\mathrm{CF}$ & LF & $\mathrm{FF}$ & $\mathrm{NF}$ \\
\hline Blocos & 2 & 919,24 & 8,28 & 15,66 & 42,57 & 0,028 & $5.160,97$ \\
\hline Progênies & 15 & $1.630,64 *$ & $84,09 *$ & $84,56 *$ & 65,35 & 0,009 & $690,11 *$ \\
\hline Entre parcelas & 30 & 706,41 & 40,58 & 41,90 & 45,55 & 0,008 & 314,40 \\
\hline Dentro de parcelas & 164 & 778,70 & 60,38 & 33,56 & 33,86 & 0,012 & 367,83 \\
\hline Média & & 149,22 & 45,33 & 74,35 & 72,60 & 1,033 & 47,36 \\
\hline $\mathrm{CV}_{\exp }(\%)$ & & 9,74 & 9,37 & 4,76 & 5,08 & 4,83 & 20,48 \\
\hline $\mathrm{h}_{\mathrm{m}}^{2}$ & & 0,57 & 0,28 & 0,51 & 0,30 & 0,11 & 0,54 \\
\hline $\mathrm{h}_{\mathrm{d}}^{2}$ & & 0,36 & 0,17 & 0,38 & 0,17 & 0,03 & 0,31 \\
\hline $\mathrm{CV}_{\mathrm{ge}}(\%)$ & & 6,43 & 3,39 & 2,77 & 1,94 & 0,96 & 12,92 \\
\hline $\mathrm{CV}_{\mathrm{gd}}(\%)$ & & 11,14 & 5,87 & 4,81 & 3,35 & 1,67 & 22,39 \\
\hline
\end{tabular}


de considerável variação dentro das progênies pode garantir ganhos, quando a seleção for praticada dentro de progênies.

Em estudo com progênies de meios-irmãos de maracujá-amarelo, obtidas de acordo com o delineamento I, em população composta pelas variedades Maguary, Yellow Master e seleções de São Francisco do Itabapoana, Gonçalves et al. (2007) também verificaram diferenças significativas entre médias de progênies, em relação aos caracteres número de frutos por planta e peso e comprimento de frutos, o que evidencia a ampla variabilidade genética e a potencialidade do processo de seleção desses genótipos, com a finalidade de desenvolvimento de populações promissoras.

Os coeficientes de variação experimentais $\left(\mathrm{CV}_{\exp }\right)$ variaram de $4,76 \%$ (comprimento dos frutos) a 20,48\% (número de frutos por planta). Gonçalves et al. (2007) e Martins et al. (2003b) estimaram para número de frutos por planta, $\mathrm{CV}_{\text {exp }}$ de 47,13 e $55,7 \%$, respectivamente. Considerando-se a origem do germoplasma utilizado, os valores observados no presente trabalho indicam boa precisão experimental. Além disso, os coeficientes de variação genética dentro de progênies foram aproximadamente $73 \%$ maiores do que entre progênies, o que indica a viabilidade de seleção da população utilizada neste trabalho.

Os valores das estimativas dos coeficientes de herdabilidade no sentido restrito, em médias de progênies $\left(\mathrm{h}_{\mathrm{m}}^{2}\right)$, variaram de 0,11 a 0,57 , e as maiores herdabilidades (acima de 0,50) foram encontradas em comprimento dos frutos, número de frutos por planta e peso de fruto. Altos valores de herdabilidade no sentido amplo, quanto ao número de frutos $(0,92)$ e ao comprimento de frutos $(0,83)$, também foram obtidos por Viana et al. (2004). Nesse mesmo trabalho, os autores estimaram herdabilidade zero com relação ao rendimento de polpa, enquanto no presente trabalho encontraram-se valores de 0,28 para $_{\mathrm{m}}^{2}$ (Tabela 1 ). Embora, essas herdabilidades possuam magnitudes intermediárias, a seleção entre progênies pode ser uma estratégia de melhoramento viável para essa população. Entretanto, os valores das estimativas de herdabilidade dentro de progênies $\left(\mathrm{h}_{\mathrm{d}}^{2}\right)$ situaram-se entre 0,03 e 0,38 , com tendência de maiores valores para os caracteres comprimento dos frutos, número de frutos por planta e peso de fruto.
Conforme esperado, as estimativas dos coeficientes de correlação genotípica e fenotípica, em médias de progênies, entre os caracteres peso $\mathrm{x}$ comprimento de frutos, peso $\mathrm{x}$ largura de frutos, e comprimento $\mathrm{x}$ largura de frutos foram positivas e de alta magnitude (Tabela 2). Quanto a: peso de frutos x rendimento de polpa, peso $\mathrm{x}$ formato do fruto, peso x número de frutos, comprimento x número de frutos, largura $\mathrm{x}$ formato dos frutos, e largura $\mathrm{x}$ número de frutos, somente os coeficientes de correlação genotípica foram negativos e de alta magnitude. Embora se observe que os maiores frutos também apresentam maior peso de polpa, a correlação negativa entre peso de fruto $\mathrm{x}$ rendimento de polpa pode ser explicada pelo fato de que este rendimento é uma relação entre o peso total do fruto e o peso da polpa, e neste caso há tendência ao aumento no peso da casca, que influi diretamente nesta relação. Essas correlações negativas indicam que quando se pratica a seleção em uma delas, espera-se uma alta resposta correlacionada negativa na outra, o que constitui problema, uma vez que o sentido da seleção é o mesmo para tais caracteres (Paula et al., 2002).

As correlações próximas de zero ou negativas de pequena magnitude como: rendimento de polpa $\mathrm{x}$ (comprimento, largura, formato e número de frutos); comprimento $\mathrm{x}$ formato de frutos e formato $\mathrm{x}$ número de frutos (Tabela 2), demonstram que a seleção para esses caracteres, no maracujá-amarelo, pode ser feita de forma independente e que não há

Tabela 2. Estimativas de correlação fenotípica e genotípica, em médias de progênies de meios-irmãos de maracujá-amarelo quanto aos caracteres peso de fruto (PF), rendimento de polpa (RP), comprimento dos frutos $(\mathrm{CF})$, largura de frutos (LF), formato dos frutos (FF) e número de frutos por planta (NF).

\begin{tabular}{lccccc}
\hline Caráter & RP & CF & LF & FF & NF \\
\hline \multicolumn{7}{c}{ Correlação fenotípica } \\
PF & $-0,090$ & $0,791^{* *}$ & $0,859^{* *}$ & $-0,019$ & $-0,064$ \\
RP & - & 0,019 & $-0,150$ & 0,209 & 0,041 \\
CF & - & - & $0,779 * *$ & 0,142 & 0,006 \\
LF & - & - & - & $-0,256$ & $-0,069$ \\
FF & - & - & - & - & 0,044 \\
\hline & $-0,498^{* *}$ & $0,799^{* *}$ & $1,000^{* *}$ & $-0,873 * *$ & $-0,749 * *$ \\
PF & - & $-0,052$ & $-0,181$ & $-0,274$ & $-0,151$ \\
RP & - & - & $0,906^{* *}$ & 0,083 & $-0,700^{* *}$ \\
CF & - & - & - & $-0,620 * *$ & $-0,854 * *$ \\
LF & - & - & - & - & $-0,015$ \\
FF & - & - &
\end{tabular}

**Significativo a $1 \%$ de probabilidade, pelo método de "bootstrap", com 5 mil simulações. 
resposta correlacionada. Observou-se tendência de os coeficientes de correlação genotípica superarem os de correlação fenotípica, o que demonstra que os fatores genéticos são mais importantes que os de ambiente, na expressão desses caracteres, em maracujá-amarelo.

As estimativas dos ganhos genéticos, independentemente do critério de seleção empregado, foram sempre maiores para o número de frutos por planta, peso de fruto e comprimento dos frutos - nesta ordem -, quando comparadas às de outros caracteres (Tabela 3). Provavelmente, tal fato se deve às maiores estimativas dos coeficientes de variação entre e dentro de progênies, bem como às estimativas dos coeficientes de herdabilidade (Tabela 1).

A seleção direta, considerando-se apenas as plantas com valores acima da média, proporcionou ganhos positivos em todos os caracteres e variou de 2,5 a $27,58 \%$. Portanto, a seleção realizada para esses caracteres de frutos proporcionou o deslocamento positivo da média, de forma a se obterem ganhos desejáveis. Apesar dos resultados satisfatórios, Cruz et al. (2004) relataram que a seleção com base em uma única característica mostra-se inadequada, pois conduz a um produto final superior com relação a essa característica, mas que pode levar a desempenhos não tão favoráveis nas demais. Assim, a adoção de métodos que possam proporcionar combinações de ganhos esperados favoráveis deve ser utilizada na avaliação dessas progênies.

Com relação aos índices de seleção, o IDGI-1 e IDGI-3, bem como o índice livre de pesos e parâmetros (Elston, 1963) apresentaram ganhos positivos para os caracteres em análise. O principal interesse nesta seleção foi a obtenção de ganhos equilibrados entre os caracteres em avaliação; embora o IDGI-1 tenha apresentado os maiores ganhos acumulados, o IDGI-3 proporcionou maior equilíbrio entre os ganhos esperados, em todos os caracteres (Tabela 3). Os ganhos genéticos de $12,61 \%$ em número de frutos por planta, com IDGI-3, são considerados de boa magnitude para o maracujá-amarelo. Gonçalves et al. (2007) utilizaram a seleção combinada e obtiveram ganhos de $18,55 \%$. Mesmo com correlações significativas entre alguns caracteres analisados (Tabela 2), foi possível promover a seleção de genótipos superiores, sem provocar mudanças indesejáveis nas progênies.

O índice clássico (IC), proposto por Smith (1936) e Hazel (1943), embora tenha demonstrado a

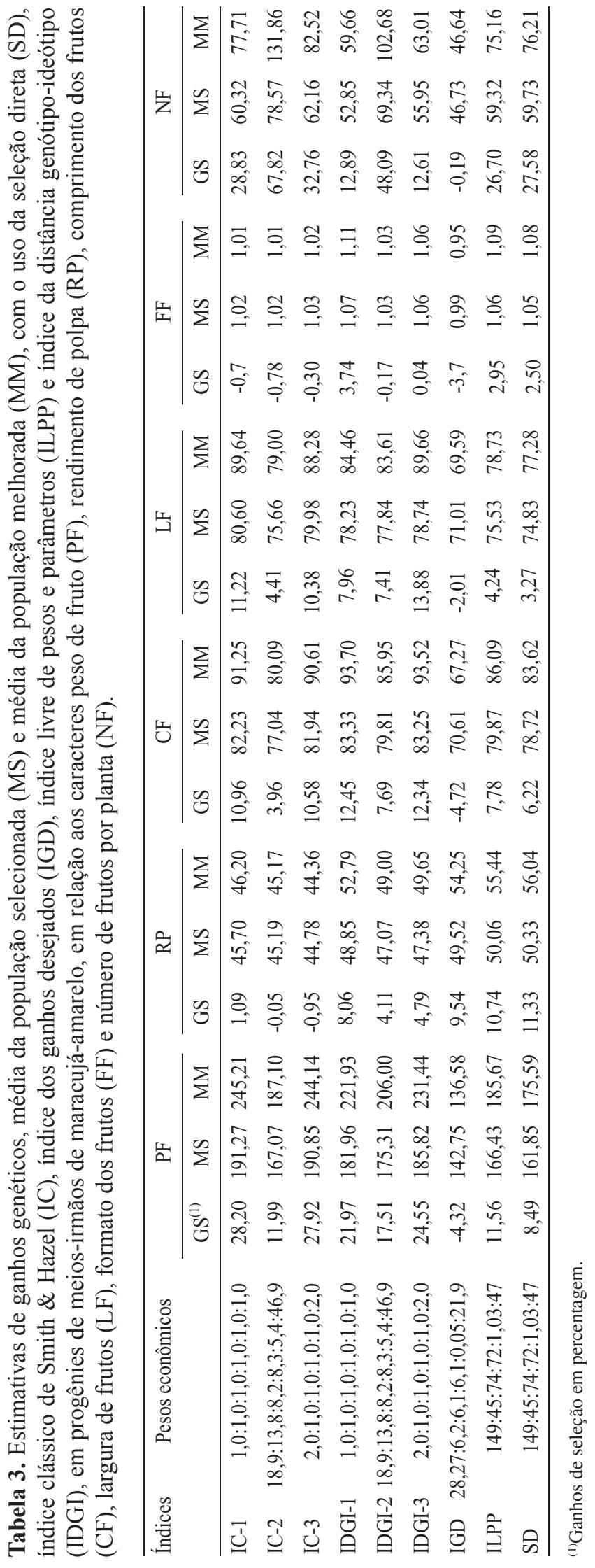


possibilidade de obtenção de maiores ganhos em peso e número de frutos, apresentou ganhos negativos quanto ao rendimento de polpa em IC-2 e IC-3, assim como em formato de fruto. Resultados semelhantes foram obtidos com o uso do IDGI-2, com ganhos negativos quanto ao formato de frutos.

Em relação ao índice dos ganhos desejados, proposto por Pesek \& Baker (1969), considerando-se como peso econômico um desvio-padrão genotípico, houve ganho somente quanto à característica rendimento de polpa. O pior desempenho do índice de ganhos desejados foi também observado por Martins et al. (2006), ao avaliar progênies de meios-irmãos de eucalipto. Portanto, o índice clássico de Smith (1936) e Hazel (1943), o índice dos ganhos desejados de Pesek \& Baker (1969) e o IDGI-2 com os pesos econômicos referidos não proporcionaram distribuição de ganhos positivos em relação a todos os caracteres, contrariamente aos propósitos do presente trabalho.

O mesmo fato foi observado por Granate et al. (2002) e Gonçalves et al. (2007), ao utilizar o coeficiente de variação genética como peso econômico, na avaliação de progênies de milho-pipoca e maracujá-amarelo, respectivamente. Apesar desses resultados, Cruz et al. (2004) argumentam que o coeficiente de variação genética apresenta propriedades interessantes nesses casos, pois é adimensional e diretamente proporcional à variabilidade genética presente.

Na utilização dos índices de seleção, foram testados pesos aleatórios até que se chegasse a um patamar de ganhos preditos como satisfatórios, ou seja, o mais perto possível do ganho direto em número de frutos por planta, sem que ocorresse queda em outros caracteres. Cruz (1990) considerou como peso mais apropriado o uso do coeficiente de variação genética, na predição de ganhos em milho. Granate et al. (2002) trabalharam com milho-pipoca e não obtiveram resultados desejados ao utilizá-los na predição de ganhos. No presente trabalho, o uso do coeficiente de variação genética foi testado como peso para os índices, mas mostrou-se inadequado, pois, apresentou ganhos pequenos e, em alguns caracteres, negativos.

Ao avaliar progênies de meios-irmãos de virola (Virola surinamensis Warb.), Maêda et al. (2001) demonstraram que o uso do índice clássico, com diferentes pesos econômicos, não possibilitou grandes diferenças em ganhos genéticos, pois o método sempre selecionava as mesmas progênies e indivíduos dentro dessas progênies, o que resultava em estimativas de ganhos muito próximas. Este fato não foi observado com o maracujá-amarelo, uma vez que todos os pesos utilizados resultaram em diferentes proporções de ganhos, em relação a todos os caracteres.

No caso do maracujá-amarelo, os índices de seleção IDGI-1, IDGI-3 e o índice livre de pesos e parâmetros (Elston, 1963), de modo geral, foram vantajosos em relação ao processo de seleção direta, e possibilitaram maiores ganhos desejáveis, ou seja, plantas com maior peso de fruto, rendimento de polpa, comprimento e largura de frutos, formato de frutos mais ovalados e com maior número de frutos por planta. As plantas selecionadas com o uso desses índices de seleção serão recombinadas entre si, para a formação de um novo ciclo de seleção, com o objetivo de desenvolvimento de novas variedades de maracujazeiro.

Resultados contraditórios foram observados em eucalipto (Martins et al., 2003a), em que a seleção direta e indireta, entre médias de famílias, não foi eficiente em proporcionar distribuição adequada de ganhos esperados; porém, o uso dos índices de seleção mostrou melhor eficiência na seleção. Todavia, Maêda et al. (2001) demonstraram que a seleção combinada foi o critério que apresentou os maiores ganhos com a seleção, em virola. Ainda, a seleção direta foi mais eficiente na obtenção de ganhos genéticos, em relação ao índice clássico e ao índice dos ganhos desejados.

De modo geral, existem contradições em relação à superioridade na predição de ganhos genéticos de um ou outro índice de seleção. Por exemplo, alguns trabalhos demonstraram a superioridade do índice clássico, na predição de ganhos nos processos de seleção em pínus e eucalipto (Allen, 1992; Martins et al., 2006), enquanto outros trabalhos demonstraram o contrário, em Virola surinamensis (Maêda et al., 2001) e maracujá-amarelo (Gonçalves et al., 2007).

No maracujá-amarelo, os ganhos em peso de frutos devem ser acompanhados pelo maior rendimento de polpa, dimensões e formato mais ovalado do fruto, além do maior número de frutos por planta, a fim de garantir maior produtividade. Os resultados do presente trabalho indicam a potencialidade da implementação dessa ferramenta estatística, no processo de seleção de progênies de maracujá-amarelo, para se obterem ganhos genéticos consistentes e equilibrados, nos diversos caracteres em análise, sobretudo com o índice da distância genótipo-ideótipo sugerido por Cruz (2006a). 


\section{Conclusões}

1. A alta variabilidade genética, entre e dentro de progênies de meios-irmãos de maracujá-amarelo, permite o estabelecimento de diversas estratégias de seleção, com o objetivo de se aumentar a freqüência dos alelos favoráveis da população.

2. O uso da seleção direta proporciona ganhos genéticos positivos em relação aos caracteres peso de fruto, rendimento de polpa, comprimento dos frutos, largura de frutos, formato do fruto e número de frutos por planta.

3. Apesar do progresso esperado com o uso da seleção direta, o índice da distância genótipo-ideótipo mostra-se o mais promissor, na avaliação de progênies de maracujá-amarelo, e proporciona maior ganho de seleção, de forma equilibrada, em todos os caracteres de frutos analisados, quando se estabelece maior peso econômico para peso e número de frutos por planta.

\section{Referências}

ALLEN, P.J. Selection indices for the genetic improvement of caribbean pine to increase sawn timber production. Australian Forestry, v.55, p.90-95, 1992.

BRUCKNER, C.H.; MELETTI, L.M.M.; OTONI, W.C.; ZERBINI JUNIOR, F.M. Maracujazeiro. In: BRUCKNER, C.H. Melhoramento de fruteiras tropicais. Viçosa: UFV, 2002. p.373-409.

CRUZ, C.D. Aplicação de algumas técnicas multivariadas no melhoramento de plantas. 1990. 188p. Tese (Doutorado) - Escola Superior de Agricultura Luiz de Queiroz, Piracicaba.

CRUZ, C.D. Programa Genes: biometria. Viçosa: UFV, 2006a. v.1. 382p.

CRUZ,. C.D. Programa Genes: estatística experimental e matrizes. Viçosa: UFV, 2006b. 285p.

CRUZ, C.D.; REGAZZI, A.J.; CARNEIRO, P.C.S. Modelos biométricos aplicados ao melhoramento genético. 3.ed. Viçosa: UFV, 2004. v.1. 480p.

ELSTON, R.C. A weight-free index for the purpose of ranking or selection with respect to several traits at a time. Biometrics, v.19, p.85-97, 1963.

GARCIA, A.A.F.; SOUZA JÚNIOR, C.L. de. Comparação de índices de seleção não paramétricos para a seleção de cultivares. Bragantia, v.58, p.253-267, 1999.

GONÇALVES, G.M.; VIANA, A.P.; BEZERRA NETO, F.V.; PEREIRA, M.G.; PEREIRA, T.N.S. Seleção e herdabilidade na predição de ganhos genéticos em maracujá-amarelo. Pesquisa Agropecuária Brasileira, v.42, p.193-198, 2007.
GRANATE, M.J.; CRUZ, C.D.; PACHECO, C.A.P. Predição de ganho genético com diferentes índices de seleção no milho-pipoca CMS-43. Pesquisa Agropecuária Brasileira, v.37, p.1001-1008, 2002.

HAZEL, L.N. The genetic basis for constructing selection indexes. Genetics, v.28, p.476-490, 1943.

INGLEZ DE SOUSA, J.S.; MELETTI, L.M.M. Maracujá: espécies, variedades e cultivo. Piracicaba: Fealq, 1997. 179p.

MAÊDA, J.M.; PIRES, I.E.; BORGES, R. de C.G.; CRUZ, C.D. Critérios de seleção uni e multivariados no melhoramento genético da Virola surinamensis Warb. Floresta e Ambiente, v.8, p.61-69, 2001.

MARTINS, I.S.; CRUZ, C.D.; REGAZZI, A.J.; PIRES, I.E. Eficiência da seleção univariada direta e indireta e de índices de seleção em Eucalyptus grandis. Revista Árvore, v.27, p.327-333, 2003a.

MARTINS, I.S.; MARTINS, R.C.C.; PINHO, D.S. Alternativas de índices de seleção em uma população de Eucalyptus grandis Hill ex Maiden. Cerne, v.12, p.287-291, 2006.

MARTINS, M.R.; OLIVEIRA, J.C. de; DI MAURO, A.O.; SILVA, P.C. da. Avaliação de populações de maracujazeiro-doce (Passiflora alata Curtis) obtidas de polinização aberta. Revista Brasileira de Fruticultura, v.25, p.111-114, 2003b.

MELETTI, L.M.M.; SANTOS, R.R. dos; MINAMI, K. Melhoramento do maracujazeiro-amarelo: obtenção do composto IAC-27. Scientia Agricola, v.56, p.491-498, 2000.

NASCIMENTO, W.M.O. do; TOMÉ, A.T.; OLIVEIRA, M. do S.P. de; MÜLlER, C.H.; CARVALHO, J.E.U. de. Seleção de progênies de maracujazeiro-amarelo (Passiflora edulis f. flavicarpa) quanto à qualidade de frutos. Revista Brasileira de Fruticultura, v.25, p.186-188, 2003.

PAULA, R.C. de; PIRES, I.E.; BORGES, R. de C.G.; CRUZ, C.D. Predição de ganhos genéticos em melhoramento florestal. Pesquisa Agropecuária Brasileira, v.37, p.159-165, 2002.

PESEK, J.; BAKER, R.J. Desired improvement in relation to selection indices. Canadian Journal of Plant Science, v.49, p.803-804, 1969.

SILVA, R.G. Métodos de genética quantitativa aplicados ao melhoramento animal. Ribeirão Preto: Sociedade Brasileira de Genética, 1982. 162p.

SMITH, H.F. A discriminant function for plant selection. Annals of Eugenics, v.7, p.240-250, 1936.

SUASSUNA, T. de M.F.; BRUCKNER, C.H.; CARVALHO, C.R. de; BORÉM, A. Self-incompatibility in passionfruit: evidence of gametophytic-sporophytic control. Theoretical and Applied Genetics, v.106, p.298-302, 2003.

VIANA, A.P.; PEREIRA, T.N.S.; PEREIRA, M.G.; AMARAL JÚNIOR, A.T. do; SOUZA, M.M. de; MALDONADO, J.F.M. Parâmetros genéticos em populações de maracujazeiro-amarelo. Revista Ceres, v.51, p.541-551, 2004.

Recebido em 21 de julho de 2008 e aprovado em 30 de outubro de 2008 
